\title{
Effects of green tea consumption and aerobic- resistance training on lipid profile and body composition in overweight and obese postmenopausal women
}

\author{
Zahra Hojjati Zidashti ${ }^{1}$, Elaheh heydari ${ }^{2}$, Fatemeh Izaddoust $^{3}$ \\ ${ }^{I}$ Associate Professor, Department of Physical Education and Sport Sciences, Rasht Branch, Islamic Azad University, \\ Rasht, Iran \\ ${ }^{2}$ MA, Department of Physical Education and Sport Sciences, Rasht Branch, Islamic Azad University, Rasht, Iran \\ ${ }^{3}$ PhD Candidate, Young Researchers and Elite Club, Rasht Branch, Islamic Azad University, Rasht, Iran
}

\begin{abstract}
Background: It seems that green tea and exercise training may have benefits for improving body composition and blood lipids. However, there are limited documents in the menopause population. Therefore, the aim of this study was to evaluate effects of green tea consumption and aerobic- resistance training on lipid profile and body composition in overweight and obese postmenopausal women.

Materials and methods: Using a semi-experimental design, 20 menopausal volunteers women were randomly assigned to experimental $(\mathrm{n}=10$, aerobic-resistance training and green tea consumption) or a control ( $\mathrm{n}=10$, no intervention). Intervention group received daily consumption of green tea (340 $\mathrm{mg}$ per day) and aerobic- resistance exercise training (three 60 min sessions per week) for 6 weeks. Subjects were tested for changes in body composition and serum lipids before and after the end of the intervention period. Data were analyzed using independent $\mathrm{t}$ - test, Mann-Whitney $\mathrm{U}$, paired $\mathrm{t}$ - test and Wilcoxon by SPSS software version 16.

Results: Body composition analysis revealed reduction in BMI $(\mathrm{p}=0.005)$ and body fat percentage $(\mathrm{p}-0.003)$ after 6-week intervention. However, there was no significant changes in WHR and blood lipids in the intervention group. In otherwise, there were no significant differences in all measurement, except body fat percentage $(\mathrm{p}=0.013)$, in between groups analysis.

Conclusion: According to the study results, it is recommended that green tea combined with aerobicresistance training are used for improving body composition in menopausal women.

Keywords: Aerobic training, Resistance training, Green tea, Body composition.

Cited as: Hojjati Zidashti Z, heydari E, Izaddoust F. Effects of green tea consumption and aerobic- resistance training on lipid profile and body composition in overweight and obese postmenopausal women. Medical Science Journal of Islamic Azad University, Tehran
\end{abstract} Medical Branch 2020; 30(1): 67-74.

Correspondence to: Fatemeh Izaddoust

Tel: +9809113316478

E-mail: fa.izaddoust@gmail.com

ORCID ID: 0000-0001-9680-6364

Received: 21 Jun 2019; Accepted: 10 Sep 2019 
مجله علوم يزشكى دانشكاه آزاد اسلامى

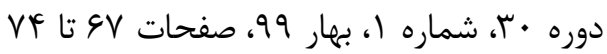

Original

Article

\section{اثر مصرف جاى سبز و تمرين هوازى - مقاومتى بر نيمرخ لييبدى و تركيب بدن زنان يائسه داراى اضافه وزن و جاق نواق}

\section{زهرا حجتى ذى دشتى '، الهه حيدرى ‘، فاطمه ايزددوست}

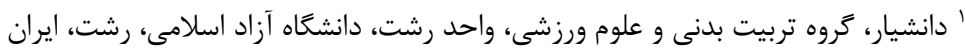

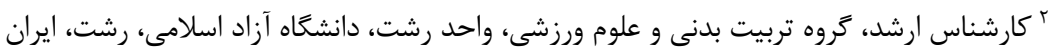

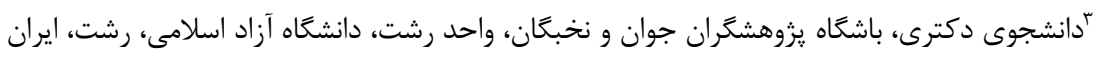

جـكبه

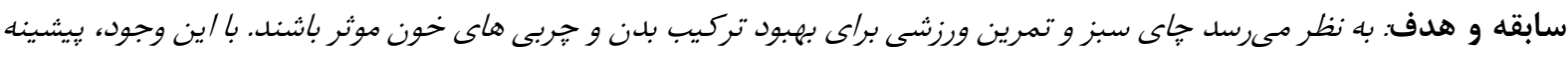

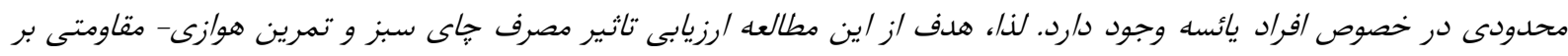

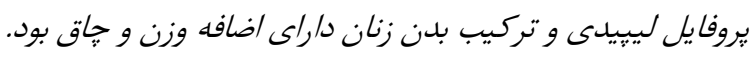

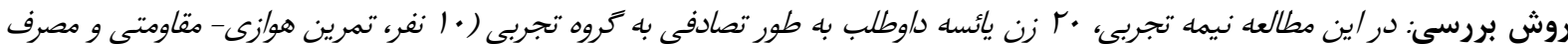

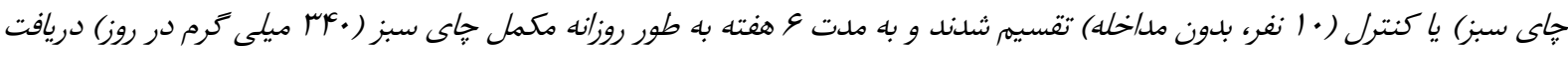

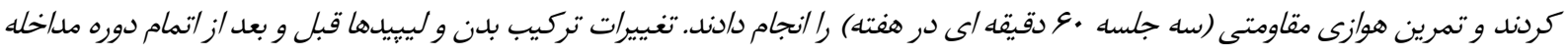

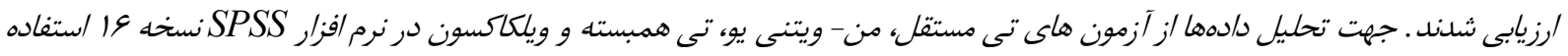

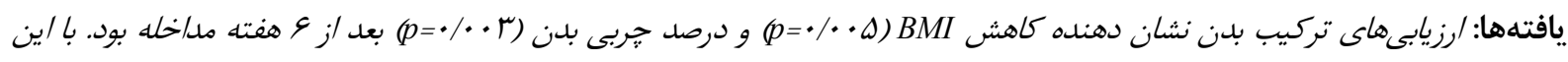

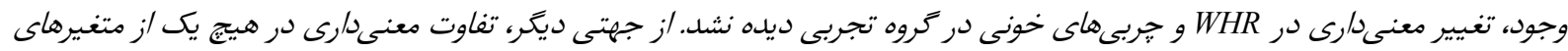

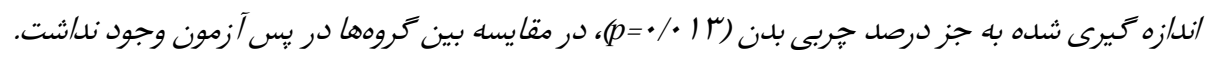

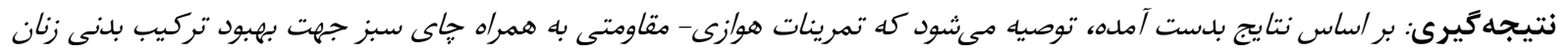
يائسه /ستفاده شود.

وازگكان كليدى: تمرين هوازى، تمرين مقاومتى، جاى سبز، تركيب بلن.

ناشى از آن همراه بوده است. در ايران كزارش شده كه بـ بـيش از مقدمه

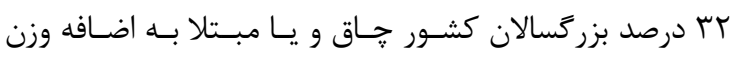

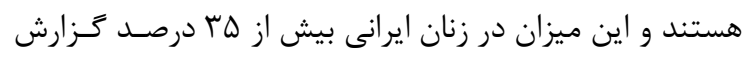

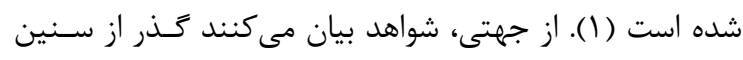

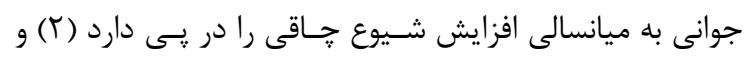

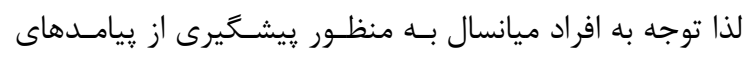

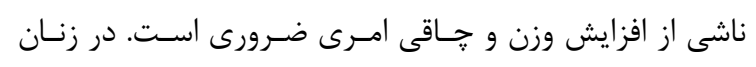

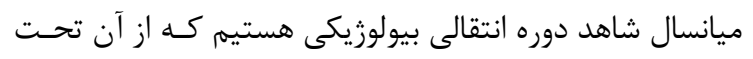

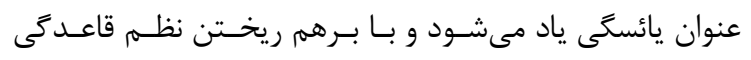

$$
\begin{aligned}
& \text { شيوع اضافه وزن و خاقى در طول سه دهه اخير افزايش هشت }
\end{aligned}
$$

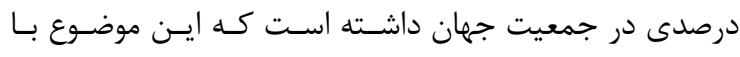

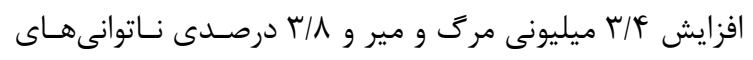

آدرس نويسنده مسئول: رشت، كروه تربيت بلدنى و علوم ورزشى، دانشكاه آزاد اسلامى واحـد رشـت، فاطمه ايزدوست (email: fa.izaddoust@gmail.com) ORCID ID: 0000-0001-9680-6364

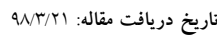
تاريخ بذيرش مقاله: 
حركت و هـر حركت • ا تكـرار بـا •و ثانيـه اسـتراحت بـين

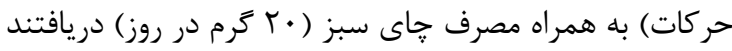

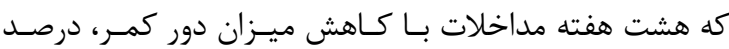
جربى بدن و ترى گليسريد و افـزايش وزن تـوده بـدون جربسى همراه بود. با اين حال تغييرى در BMI، كلسـترول، HDL-C و LDL-C

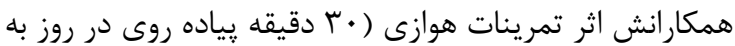
مدت צ روز در هفته) به همراه مكمل سازى جاى سبز (مصرف

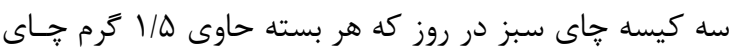

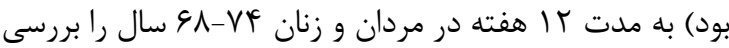

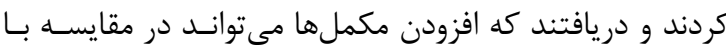
انجام تمرينات به تنهايى، موجب كاهش وزن و دور كمر شـود.

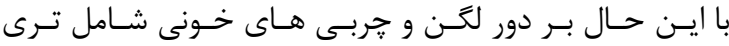

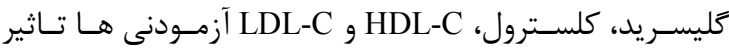
معنى دارى نداشت (ع) (1). ماكى و همكارانش نيز نشـان دادنـد

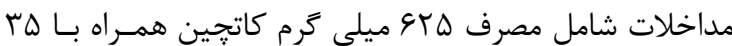

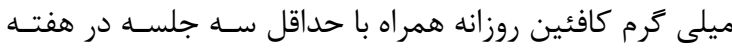

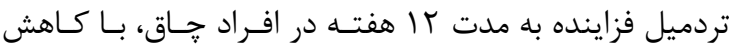
جربى زير جلدى و ترى كليسريد سرم و عدم تغيير در WHR،

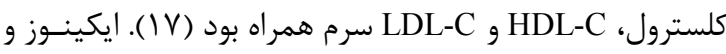

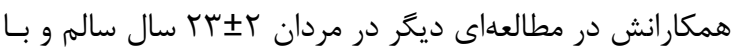

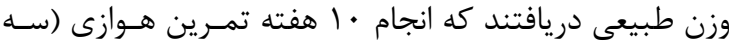
جلسه در هفته، هر جلسه •و دقيقه فعاليت بـر روى دوجرخــه كارسنج بـا • و درصـد حـداكثر اكسـيزن مصـرفى) بـه همـراه

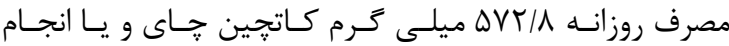

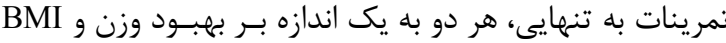

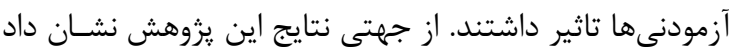
كه انجام تمرينات به همراه مصـرف كـاتهين موجـب افـزايش

استفاده از جربى كل بدن در حين ورزش ميىشود (1).

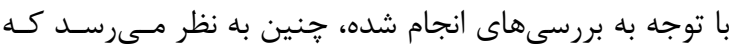

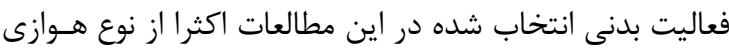

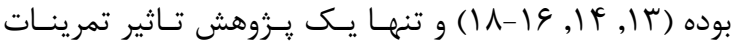
مقاومتى (ه1) را ارزيابى كرده است، حال آنكه تـاثير تمرينـات

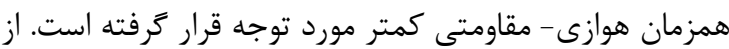
سويى، با توجه به تاثيرات يائسگى بر ميزان ترشح هورمونها و هوري

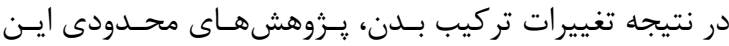

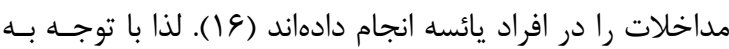
آنجه بيان شد، هدف از يزوهش حاضر بررسى اثر مصرف جـاى

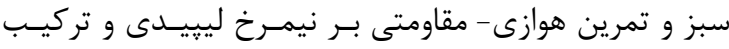

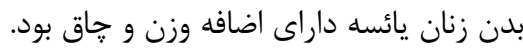

شروع، با طولانى شدن فواصل قاعدگى ادامه يافته و در ادامه با

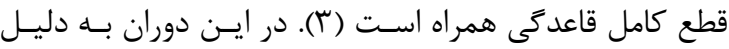

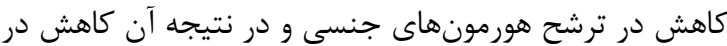
ميزان انرزى مصرفى و اكسيداسيون جربىها، تغييرات تركيـب

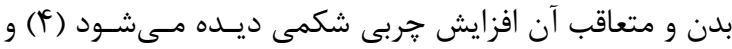

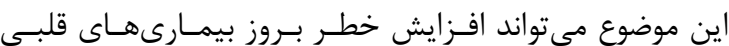

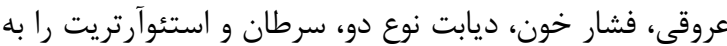

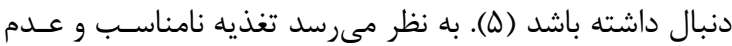

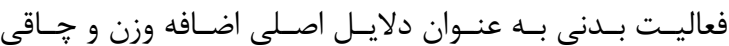
محسوب مىشوند (9) و لذا مداخلات ييشخيرانه و درمانى بهتر است از طريق اين دو عامل مهرم انجام گيرند.

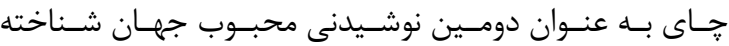
مىشود كه از ميان انواع آن، جـاى سـبز حـدود · ب درصـد از ¥اى توليدى را به خود اختصـاص داده و بــه طـور وسـيعى در

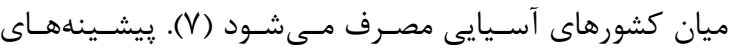
يزوهش نشان مى دهند كه مصرف جاى سبز بـهـ دليـل مقـادير

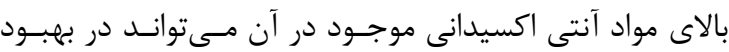
سطوح جربىهاى خونى و تركيب بدن موثر باشد كه اين اثرات از طريق مكانيسمهاى متعددى ميسر مىشود. به عنوان مثـال،

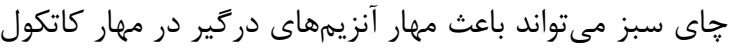

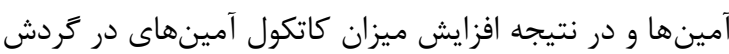
شود (^). از جهتى، در كاهش زنهاى آدييوزنيك (9)، افزايش بيان زنهاى لييوليتيك و آنزيمهاى درگير در بتا اكسيداسيون

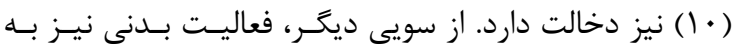
عنوان راهكارى مناسب براى افزايش متابوليسم جربىهاى بدن محسوب مىشود. فعاليت بدنى احتمـالا باعـث افـزايش ميـزان

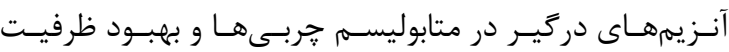
اكسيداسيون جربـىها در عضلات شـده و از ايسن رو بـهـ عنــوان عاملى موثر در بهبود سطوح جربى هاى خون و تركيب بدن به شمار مىرود (1 (1). از ميان شيوههاى متفاوت تمرينى، به نظـر

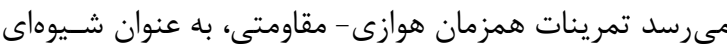
مناسب براى تمرين، باعث به حداكثر رسـاندن مزايـاى هــر دو تمرينات هوازى و مقاومتى شود (T (I). با توجه به تاثيرات مصرف جاى سبز و فعاليت بـدنى، بــه نظـــ مىرسد كه استفاده همزمان از هر دو عامل به عنوان راهكـارى مناسب به منظور هم افزايشى تاثيرات بـراى كنتــرل و درمـان

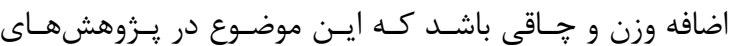

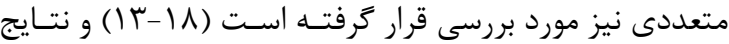
ضد و نقيضى بدسـت آمـده اسـت. كاردوسـو و همكسارانش در بررسـى تـاثير تمرينـات مقـاومتى (سـه جلســـ در هفتــه، • 


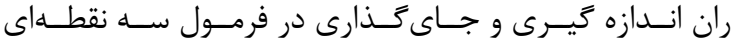

جكسون- يولارك محاسبه شد (19).

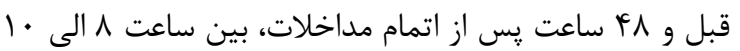

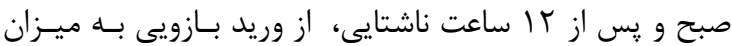

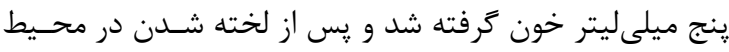

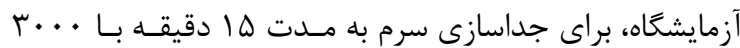
دور در دقيقه سانتريفيوز شد. ميزان ترى كليسريد و كلسترول

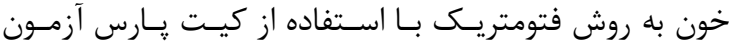
ساخت ايران، و مقادير لييويروتئين كم جخَال ( Low density

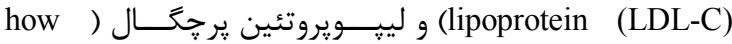
به روش آنزيمى و با اسـتفاده

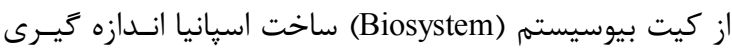

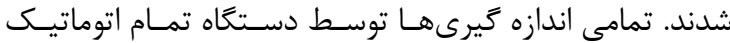
هيتاجى مدل r ••9 ساخت زإِن انجام شد.

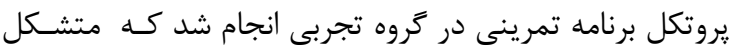

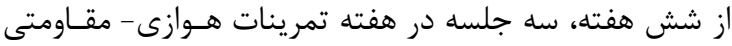

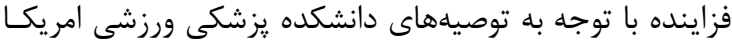

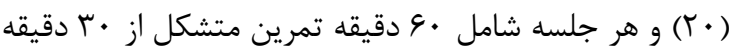

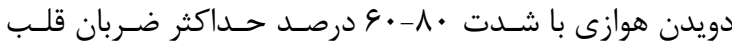

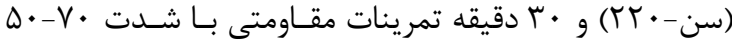
درصد يك تكرار بيشـينه بـود. تمر ينـات هـوازى در هفتـه اول

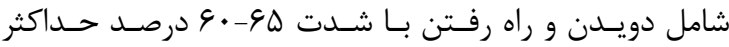

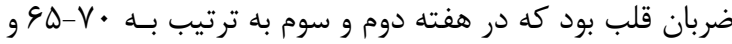
V •-VD

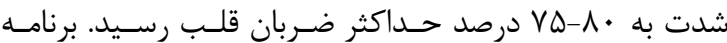

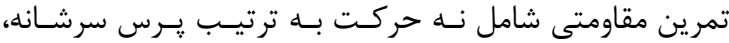

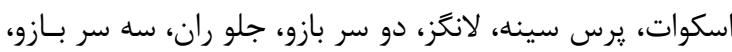
بشت ران و دراز نشست بود كه توسـط وزنـهـ هـاى آزاد مبــارز

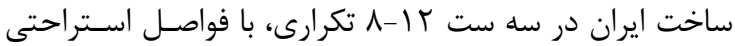

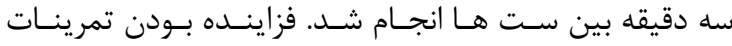

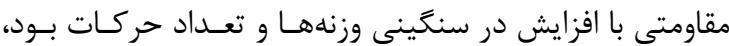

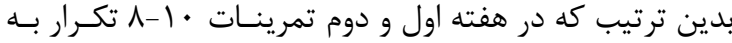

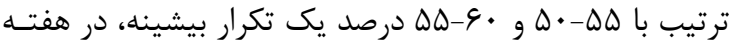

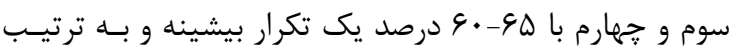

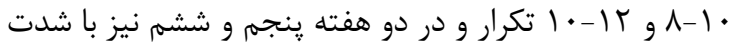

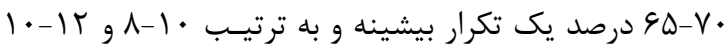

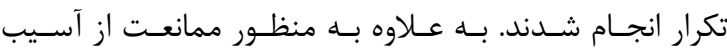

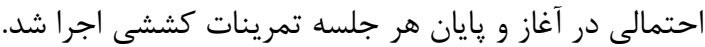

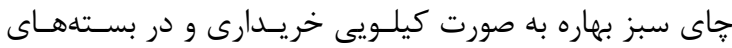

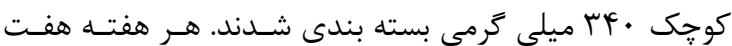

مواد و روشها

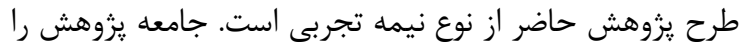

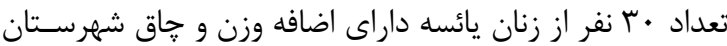

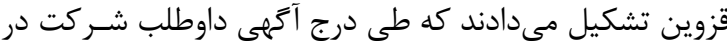

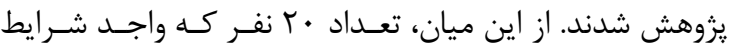

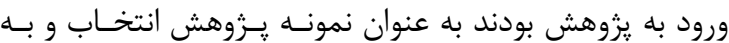

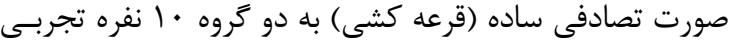

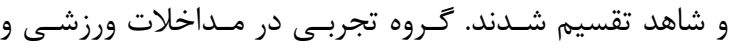
مصرف جاى سبز شـركت داده شـدند و از ايـن رو تنهـا تـاثير همزمان دو متغير مورد يزوهش قرار كرفـت و در كَروه شـاهد

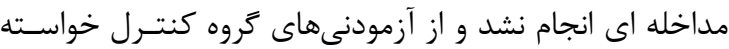

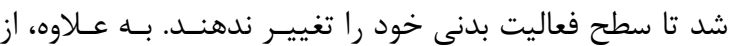

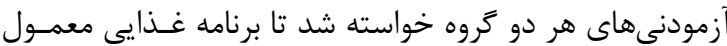
خود را در طول دوره مطالعه حفظ كنند. معيارهاى ورود شامل فاصله زمانى حداقل دو سال از آخرين خونريزى، عـدم مصـرف

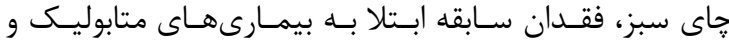
ارتويدى، فقدان هر نوع رزيم غذايى و كاهش وزن طـى شـى شـش

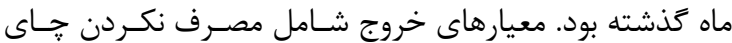

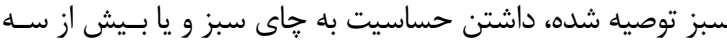

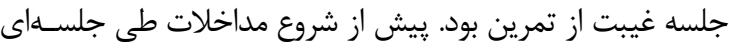

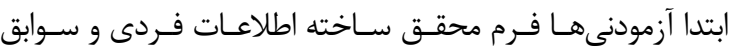
يزشكى را ير كـرده، طـرح تحقيـق، روش اجـرا و مزايــا و معايسب

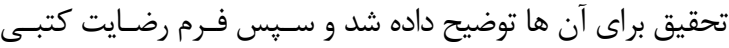

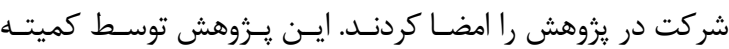

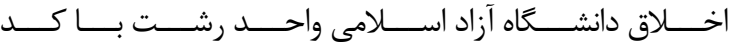
IR.IAU.RASHT.REC.1396.105 تاييسد و در مركـز كارآزمـايى داليى بالينى ايران نيز با شماره IRCT20151209025449N3 ثبت شد.

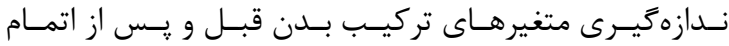

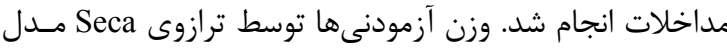

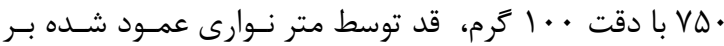

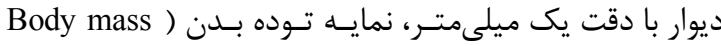
توسـط تقسـيم وزن بـر حسـب كيلـوخرم بــر

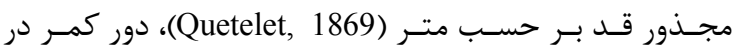

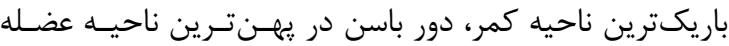
كلوتئال، نسبت دور كمـر بـه دور باسـن ( Waist to hip ratio

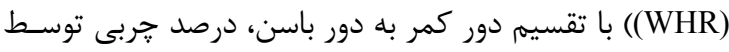

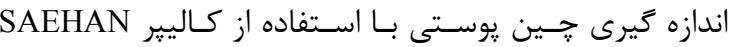
ساخت كره جنوبى در سه ناحيه سه سر بـازو، فـوق خاصـره و 


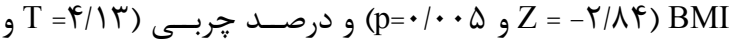

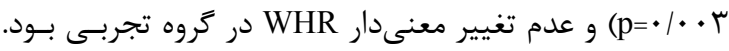
در كروه شاهد تغييرات در هر سه متغيـر يـاد شــده، معنسى نـار

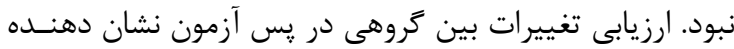

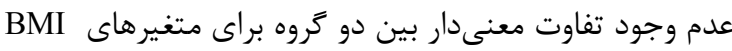

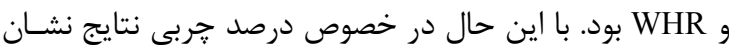

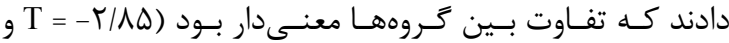

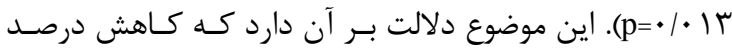

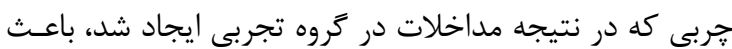
تفاوت معنىدار آن با گروه شاهد شد (جدول ؟). در بخش جربىهاى خونى، بررسى ميزان كلسترول، ترى

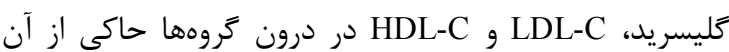
بود كه مداخلات بر بهبود خربىهاى خونى تاثير معنىدارى

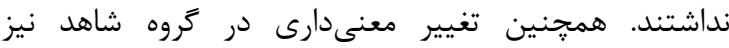

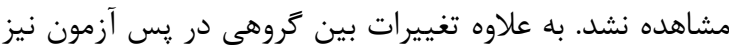

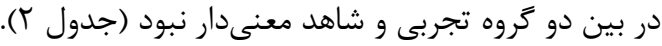

\section{بحث}

هدف از يزوهش حاضر بررسى تاثير شش هفته تمرين هوازى-

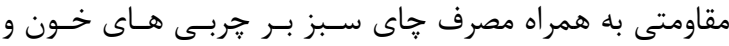

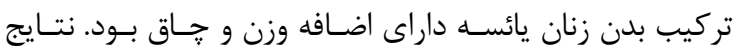
يزوهش حاضر نشان داد كه مداخلات موجب كاهش معنسى دار BMI و درصد خربى بدن آزمودنىها شد. با اين حال تغييـرات

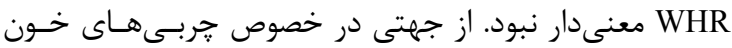
مىتوان بيان داشت كه با وجود آنكه تمايل به كاهش در ميزان
بسته به هر آزمودنى كروه تجربى داده شــ تـا هـر بسـته را در

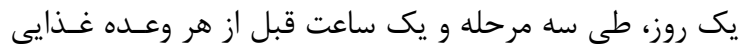

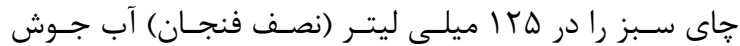

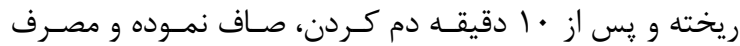

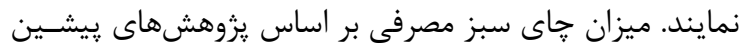

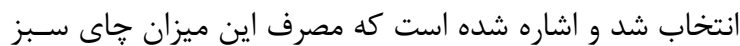

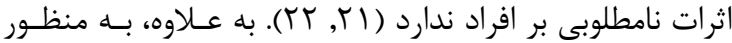

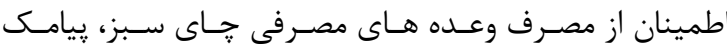
روزانهاى به آزمودنىها داده شد. جهت تحليل دادهها ابتدا نرمال بودن دادههاى مطالعهـ توسط اده آزمون شإيروويلك ارزيابى و جهت بررسى تفاوتهـاى بــين و

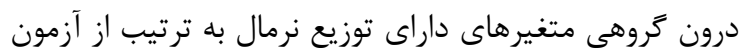

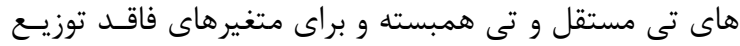

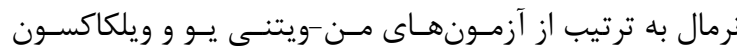

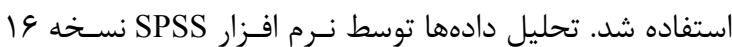
انجام و سطح معنىدارى كمتر از هـ/• در نظر ترفته شد.

\section{يافتهها}

ميانگين سنى در تروه تجربى و

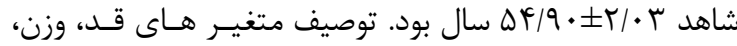

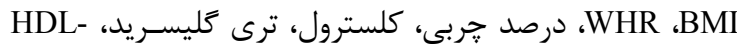

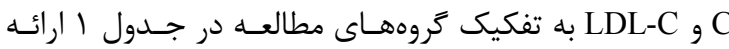

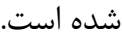

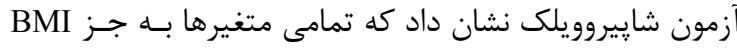

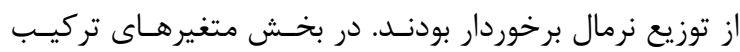

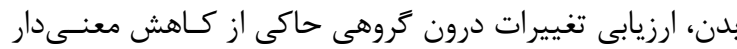

\begin{tabular}{|c|c|c|c|c|}
\hline \multicolumn{2}{|c|}{ كروه شاهد (·n=1) } & \multicolumn{2}{|c|}{ كروه تجربى (• (n=1) } & \\
\hline يس آزمون & يِيش آزمون & يس آزمون & يِيش آزمون & \\
\hline انحراف معيار ذميانكَين & انحراف معيار 土ميانگين & انحراف معيار 土ميانگين & انحراف معيار 士ميانگين & \\
\hline- & $109 / \Lambda \cdot \pm r / 94$ & - & $19 \cdot 1 \Lambda \cdot \pm N / T V$ & قد (سانتى متر) \\
\hline$\Lambda \cdot / \Lambda \Lambda \pm ץ / 99$ & $\Lambda \cdot / \Lambda r \pm \Delta / / 9$ & $\Lambda \cdot / \cdot \pm \Delta / \mathrm{V} \Delta$ & $\Lambda r / q \cdot \pm \Delta / 1$. & وزن (كيلو ترم) \\
\hline$r|/ \wedge \uparrow \pm 1 / l|$ & $r / / \Lambda \cdot \pm 1 / 1 T$ & 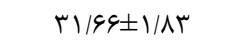 & $r r / \Lambda \cdot \pm r / \cdot r$ & (كيلوَرم بر متر مربع) BMI \\
\hline$\cdot / 9 r T \pm \cdot / r q$ & $\cdot / 9 \cdot \Delta \pm \cdot / r q$ & $. / 9 r r \pm \cdot / \cdot 9$ & $. / 9 \curlyvee 9 \pm \cdot / .9$ & WHR WHe WH \\
\hline$r N / I F \pm 1 / l \mid$ & $r N / 1 \cdot \pm 1 / 1 T$ & 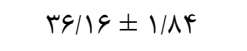 & $\Gamma \wedge / r \cdot \pm 1 / \Delta q$ & درصد خربى (درصد) \\
\hline$|V T / \cdot q \pm| \Delta / q Y$ & $|V| / \Lambda \cdot \pm|\varepsilon| \cdot r$ & $|9 T / Q \cdot \pm r / /|$ & $199 / 4 \cdot \pm r r / \Delta V$ & كلسترول (ميلى گرم بر دسى ليتر) \\
\hline $\mid \Delta \Lambda / \kappa \cdot \pm \Delta \Delta / r$ & $\mid \Delta \Lambda / r \cdot \pm \Delta \Delta / f \Delta$ & $|r \Delta / \Delta \cdot \pm 9 q /| F$ & $1 r q / \wedge \cdot \pm q 9 / \wedge$. & ترى گليسريد (ميلى گرم بر دسى ليتر) \\
\hline$Y \Psi / Y G \pm V / q \varphi$ & $\varphi \& / \Delta \cdot \pm \Lambda / \Delta \Lambda$ & $\mid \mathcal{N} / \cdot \cdot \pm I T / K \Delta$ & $F r / r \cdot \pm I r / f G$ & (ميلى گرم بر دسى ليتر) HDL-C \\
\hline $1 \cdot 1 / V \Delta \pm 1 \Delta / \%$. & I. & $\Lambda F / \Delta \cdot \pm r \Delta / \cdot 1$ & $1 \cdot 9 / 4 \cdot \pm 19 / v 9$ & LDL-C (ميلى گرم بر دسى ليتر) \\
\hline
\end{tabular}


جدول ז. مقايسه درون و بين گروهى متغيرهاى تركيب بدن و جربىهاى خونى (تعداد در هر گروه • ا نفر)

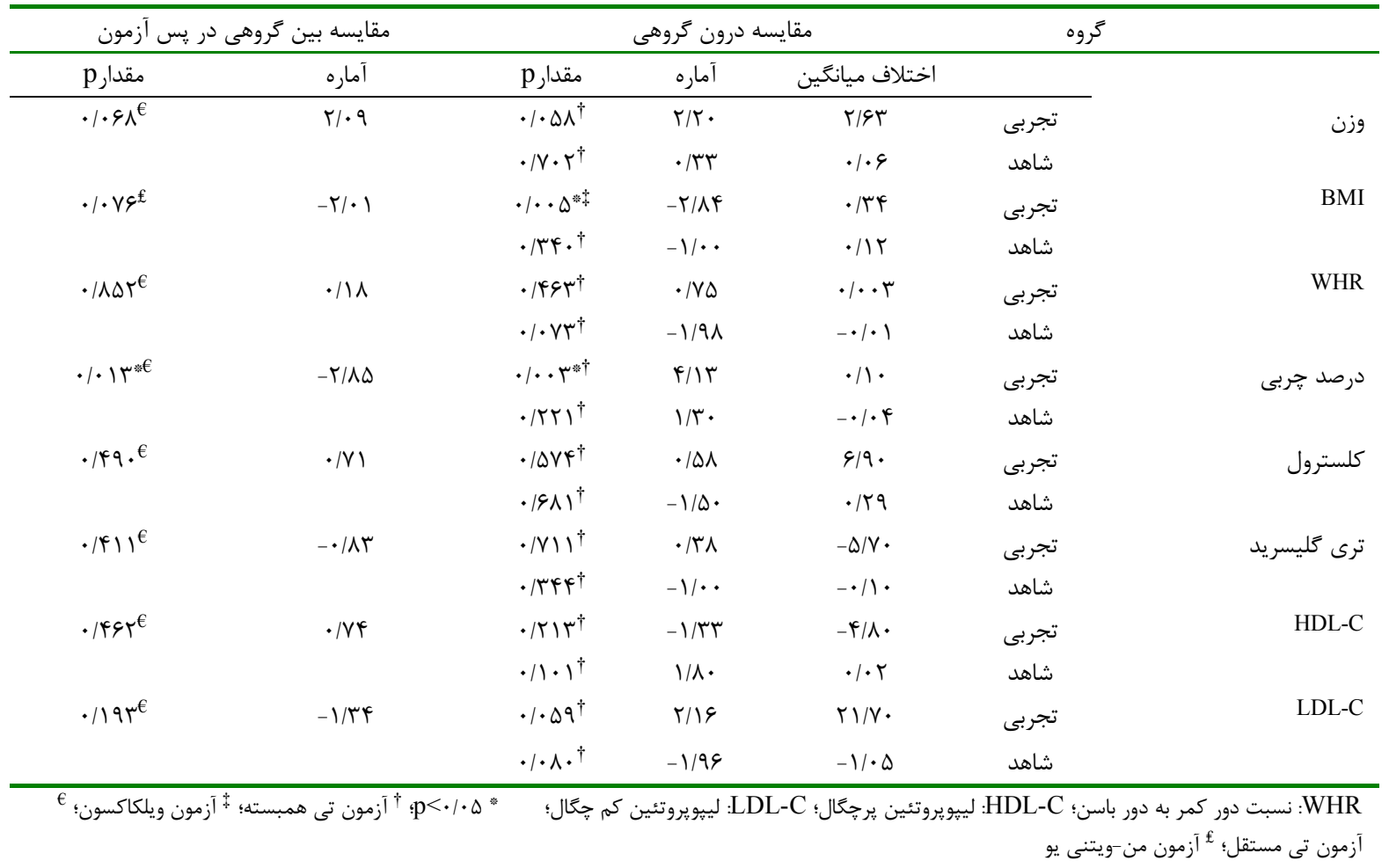

مصرف شده در يزوهشهاى ياد شده (1|-19|) بـود كـه دليـل

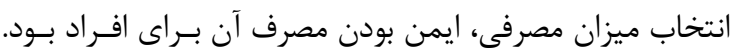

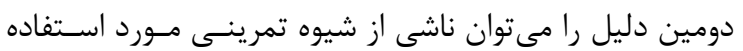

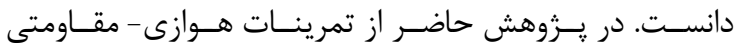
استفاده شده بود، در حـالى كـه در سـاير مطالعـات تمرينـات

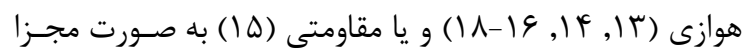
اجرا شده بودند. همجنين شدت تمرينات، ويزگگى آزمودنىها و

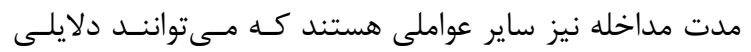
براى اختلاف نتايج بدست آمده باشند.

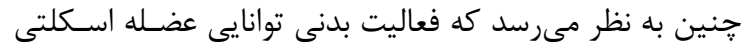

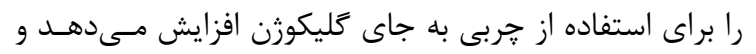

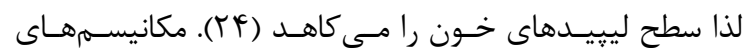
دركير در اين فرآيند شامل افزايش ميزان آنزيمهـاى لسـيتين كلسترول آسـيل ترانسـفراز (LCAT) (آنزيمسى كـهـ در انتقــال

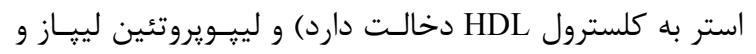
كاهش يـروتئين انتقــال دهنــده كلسـترول اسـتريفه (CETP)

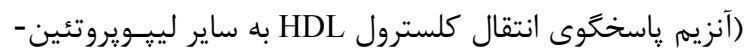

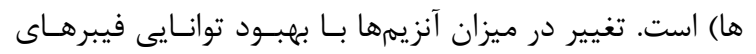

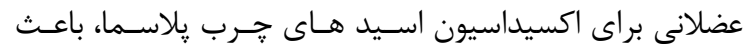
كاهش كلسترول VLDL و ترى كليسـيريد مسىشـود (1) (1). از جهتى در خصوص جاى سبز ميىتوان بيـان داشـت كـه حسدود
خـــون وجــود داشـت، امــا تغييـرات در هـيـج يـكـ از LDL-C متغيرهاى جربى خون اندازه گيرى شده، شامل كلسـترول، تـرى

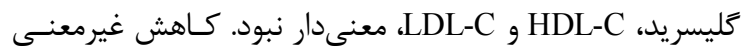
دار ميزان جربى خون در يزوهش حاضر مىتواند ناشسى از تـاثير

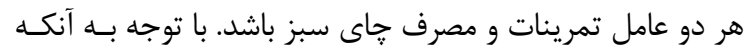

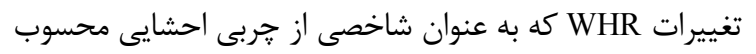
مىشود، در گروه تجربى معنى دار نبود، به نظر مىرسد تغييـرات

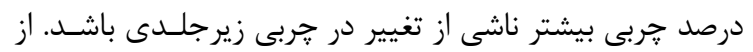

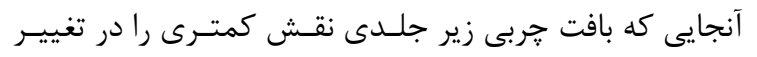

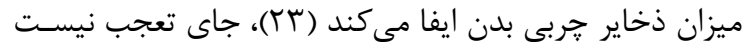

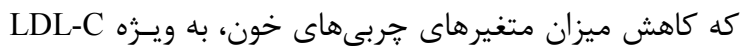

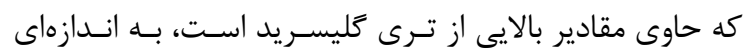
نباشد كه از نظر آمارى معنى دار شارئ شود.

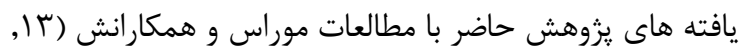

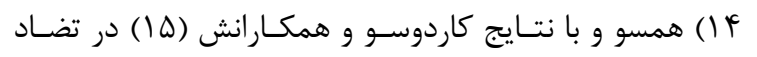

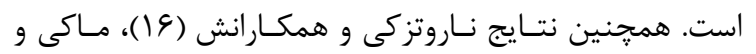

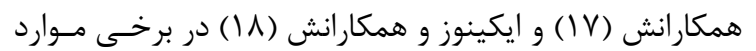

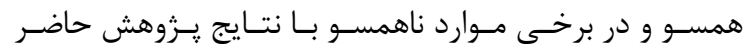

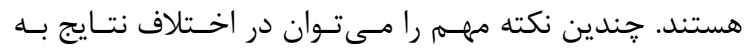

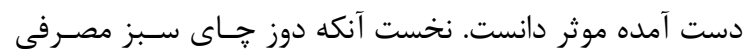

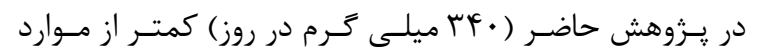


مىتوان نتيجه گَرفت كه عصاره جاى سبز براى ايجاد ساز گَارى در اكسيداسيون آنزيمها و يروتئينهاى درگير در اكسيداسيون جربى نيازمند فعاليت بدنى است. يثوهش حاضر محدوديت هايى دارد كه لازم است به آنها توجه

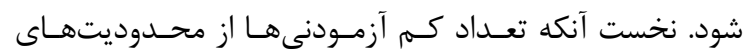

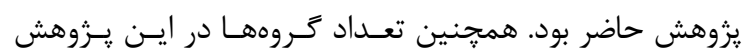

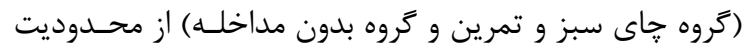
هاى ديكر اين يثزوهش است كه ميىتوانـد در نتـايج بـه دسـت

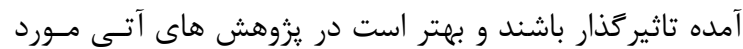
توجه قرار زيرند. به طور كلى مىتوان بيان داشت كه انجام شش هفته تمرينـات

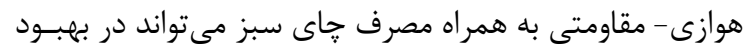
BMI بنابراين خنين برنامهاى به همراه مصرف خاى سـبز بــه عنــوان

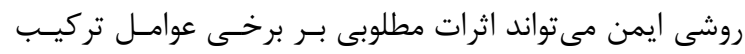

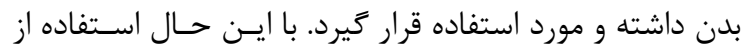

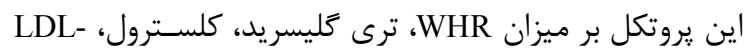
HDL-C و اثرى ندارد. C

\section{تشكر و قدردانى}

اين يزوهش حاصل يايان نامه كارشناسى ارشد است كه با حمايت دانشخاه آزاد اسلامى واحد رشت انجام شد. يزوهش درائ در كميته اخلاق دانشخاه (كد: IR.IAU.RASHT.REC.1396.105) تاييد شد و همجنين در مركز كارآزمايى بالينى ايران نيز ثبت شد داند

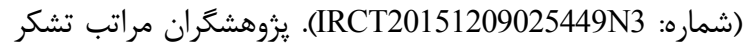
و قدردانى خود را از آزمودنىهاى محترم و تمامى افرادى كه به

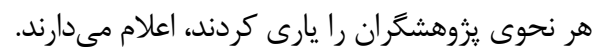

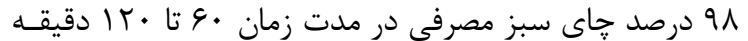
بعد از گوارش توسط باكترىهاى رودهاى و كبد در يلاسـما بـهـ صورت كنزوگه تبديل شده و تنهها كمتر از دو درصـد كـاتجين

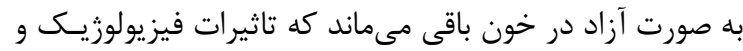

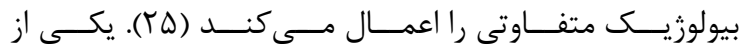
مكانيسمهايى كه جاى سبز از طريق آن ميىتواند بر متابوليسـم

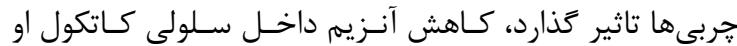
متيل ترانسفراز (Catechol-O-methyltransferase (COMT)

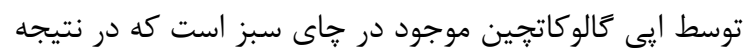

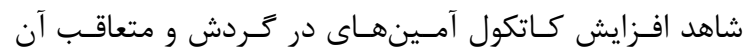

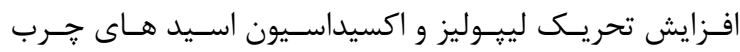

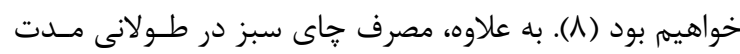
مىتواند موجب كاهش رن هاى آديبوزنيك از جملـه PPARY، يروتئين آلفا اتصالى افزايش دهنده Ccaat-enhancer ) Ccaat

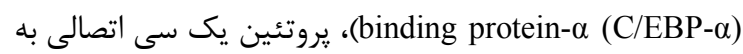
عوامـل تنظـيم كنـــده اسـترول ( sterol regulatory element r binding protein-1c (SREBP-1c)

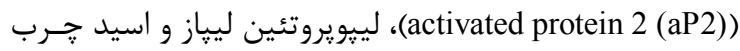

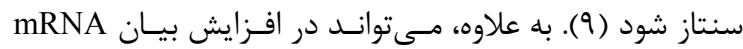

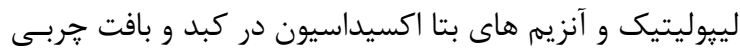

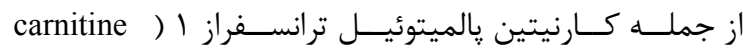
palmitoyl transporter I (CPTI)

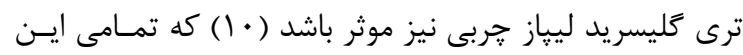

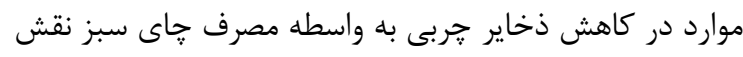
دارند. از سويى گزارش شده كه عصاره جاى سبز مسى توانـد در

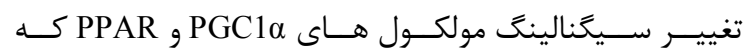

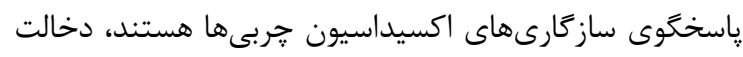
داشته و براى فعال شـدن ايـن مسـير هـاى سـيخَنالى، انجـام

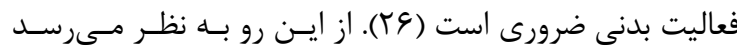

\section{REFERENCES}

1. Ng M, Fleming T, Robinson M, Thomson B, Graetz N, Margono C, et al. Global, regional, and national prevalence of overweight and obesity in children and adults during 1980-2013: a systematic analysis for the Global Burden of Disease Study 2013. Lancet 2014;384:766-81.

2. Ogden CL, Carroll MD, Fryar CD, Flegal KM. Prevalence of obesity among adults and youth: United States, 20112014. NCHS Data Brief 2015:1-8.

3. Harlow SD, Gass M, Hall JE, Lobo R, Maki P, Rebar RW, et al. Executive summary of the Stages of Reproductive Aging Workshop+ 10: addressing the unfinished agenda of staging reproductive aging. J Clin Endocrinol Metab 2012;97:1159-68.

4. Lovejoy J, Champagne C, De Jonge L, Xie H, Smith S. Increased visceral fat and decreased energy expenditure during the menopausal transition. Int J Obes 2008;32:949.

5. Jull J, Stacey D, Beach S, Dumas A, Strychar I, Ufholz L-A, et al. Lifestyle interventions targeting body weight changes during the menopause transition: a systematic review. J Obes 2014;2014.

6. James W. WHO recognition of the global obesity epidemic. Int J Obes 2008;32:S120-S6. 
7. Hayat K, Iqbal H, Malik U, Bilal U, Mushtaq S. Tea and its consumption: benefits and risks. Crit Rev Food Sci 2015;55:939-54.

8. Goldstein DS, Eisenhofer G, Kopin IJ. Sources and significance of plasma levels of catechols and their metabolites in humans. J Pharmacol Exp Ther 2003;305:800-11.

9. Chen N, Bezzina R, Hinch E, Lewandowski PA, Cameron-Smith D, Mathai ML, et al. Green tea, black tea, and epigallocatechin modify body composition, improve glucose tolerance, and differentially alter metabolic gene expression in rats fed a high-fat diet. Nutr Res 2009;29:784-93.

10. Sae-tan S, Grove KA, Kennett MJ, Lambert JD. (-)-Epigallocatechin-3-gallate increases the expression of genes related to fat oxidation in the skeletal muscle of high fat-fed mice. Food Funct 2011;2:111-16.

11. Mann S, Beedie C, Jimenez A. Differential effects of aerobic exercise, resistance training and combined exercise modalities on cholesterol and the lipid profile: review, synthesis and recommendations. Sports Med 2014;44:211-21.

12. Kang J, Ratamess N. Which comes first? Resistance before aerobic exercise or vice versa? Acsms Health Fit J 2014;18:9-14.

13. Murase T, Haramizu S, Shimotoyodome A, Tokimitsu I. Reduction of diet-induced obesity by a combination of tea-catechin intake and regular swimming. Int J Obes 2006;30:561-8.

14. Murase T ,Haramizu S, Ota N, Hase T. Tea catechin ingestion combined with habitual exercise suppresses the aging-associated decline in physical performance in senescence-accelerated mice. Am J Physiol Regul Integr Comp Physiol 2008;295:R281-9.

15. Cardoso GA, Salgado JM, Cesar MdC, Donado-Pestana CM. The effects of green tea consumption and resistance training on body composition and resting metabolic rate in overweight or obese women. J Med Food 2013;16:120-7.

16. Narotzki B, Reznick AZ, Navot-Mintzer D, Dagan B, Levy Y. Green tea and vitamin E enhance exercise-induced benefits in body composition, glucose homeostasis, and antioxidant status in elderly men and women. J Am Coll Nutr $2013 ; 32: 31-40$

17. Maki KC, Reeves MS, Farmer M, Yasunaga K, Matsuo N, Katsuragi Y, et al. Green tea catechin consumption enhances exercise-induced abdominal fat loss in overweight and obese adults. J Nutr 2009;13:264-70.

18. Ichinose $\mathrm{T}$, Nomura S, Someya $\mathrm{Y}$, Akimoto S, Tachiyashiki K, Imaizumi K. Effect of endurance training supplemented with green tea extract on substrate metabolism during exercise in humans. Scand J Med Sci Sports 2011;21:598-605.

19. Beam JR, Szymanski DJ. Validity of 2 skinfold calipers in estimating percent body fat of college-aged men and women. J Strength Cond Res 2010;24:3448-56.

20. Garber CE, Blissmer B, Deschenes MR, Franklin BA, Lamonte MJ, Lee I-M, et al. Quantity and quality of exercise for developing and maintaining cardiorespiratory, musculoskeletal, and neuromotor fitness in apparently healthy adults: guidance for prescribing exercise. Med Sci Sports Exerc 2011;43:1334-59.

21. Hill A, Coates A, Buckley J, Ross R, Thielecke F, Howe P. Can EGCG reduce abdominal fat in obese subjects? Med Sci Sports Exerc 2007:S396-402.

22. Onakpoya I, Spencer E, Heneghan C, Thompson M. The effect of green tea on blood pressure and lipid profile: a systematic review and meta-analysis of randomized clinical trials. Nutr Metab Cardiovasc Dis 2014;24:823-36.

23. Despres J. Intra-abdominal obesity: an untreated risk factor for Type 2 diabetes and cardiovascular disease. J Endocrinol Invest 2006;29:77.

24. Onakpoya IJ, Heneghan C. Effect of the novel functional fibre, polyglycoplex (PGX), on body weight and metabolic parameters: a systematic review of randomized clinical trials. J Clin Nutr 2015; 34:1109-14.

25. Kroon PA, Clifford MN, Crozier A, Day AJ, Donovan JL, Manach C, et al. How should we assess the effects of exposure to dietary polyphenols in vitro? Am J Clin Nutr 2004;80:15-21.

26. Haramizu S, Ota N, Hase T, Murase T. Catechins attenuate eccentric exercise-induced inflammation and loss of force production in muscle in senescence-accelerated mice. J Appl Physiol 2011;15:22-29. 